\section{Genetic Markers of Immunoglobulin G as Potential Risk Factors for IgG4-related Disease}

\section{To the Editor:}

Immunoglobulin (Ig) G4-related disease is a relatively new fibroinflammatory systemic condition of unknown etiology. It is usually associated with elevated serum IgG4 concentrations ${ }^{1}$. Among the disease-initiating mechanisms, host genetic factors are thought to be important, but there is a paucity of genetic studies and to date only a few probable susceptibility factors have been described ${ }^{1}$. Our aim is to spur further genetic research by postulating Ig GM allotypes - highly polymorphic hereditary antigenic determinants expressed on $\gamma$ chains - as possible risk factors for IgG4-related disease. GM (IgG marker) allotypes are encoded by 3 very closely linked genes on chromosome 14q32. They are localized on the constant region of $\gamma 1, \gamma 2$, and $\gamma 3$ chains $^{2}$. Ig $\gamma 4$ chains do not express subclassspecific unique allotypes, but they do express isoallotypes - determinants that behave as alleles in one IgG subclass (allotypes) but are also expressed in all molecules of at least one other subclass (isotypes).

Several attributes of the GM genetic system make it a likely candidate for involvement in the etiopathogenesis of IgG4-related disease. Serum IgG4 concentration, which is usually elevated in this condition, has been shown to be associated with particular GM allotypes. GM allotype analyses of sera from related and unrelated subjects showed strong association of the GM 23/n allotype (expressed on $\gamma 2$ ) with serum IgG4 concentration $^{3}$. Moreover, the effect of the GM 23 allele appeared to be additive: of the 3 genotypes in this biallelic system, serum $\operatorname{IgG} 4$ concentration was highest in GM 23+/GM 23+ homozygotes, somewhat intermediate in GM 23+/GM 23- heterozygotes, and lowest in GM 23-/GM23- homozygotes.

Atopy and asthma may represent another link between GM allotypes and IgG4-related disease. Particular GM allotypes have been shown to be associated with these allergic features ${ }^{4}$, which are commonly present in patients with IgG4-related disease ${ }^{1}$. It has been postulated that IgG4-related disease might have an infectious etiology ${ }^{1}$. Immunity to a large number of pathogens (bacteria, viruses, and parasites) is influenced by GM genes $^{2,5,6}$. It follows that GM genes could act as potential effect modifiers of pathogen-IgG4-related disease association.

IgG4 antibodies - unlike those of other IgG subclasses - can swap their arms, a biological mechanism that has been suggested to provide the basis for the antiinflammatory activity of this molecule ${ }^{7}$. Interestingly, the arginine/lysine substitution at amino acid position 409 (R409/K409) in the $\mathrm{CH} 3$ domain of IgG4, crucial for the Fab-arms exchange, characterizes an isoallotype ${ }^{8}$. R409 and $\mathrm{K} 409$ behave as alleles on IgG4 (allotypes), but they are also present on all molecules of the other IgG subclasses (isotypes). R409 has been shown to be a molecular determinant for enabling, and K409 for blocking, the Fab-arms exchange? .

Thus, examination of GM allotypes is likely to yield insights into the etiopathogenesis of IgG4-related disease. It might be relevant to add that a candidate gene approach would be necessary to delineate the role of GM genes in this disease, as these variants are not included in the widely used genotyping platforms and therefore are unlikely to be detected by genome-wide association studies of this condition ${ }^{10,11}$. IgG gene segments harboring GM alleles are highly homologous and apparently not amenable to the high-throughput genotyping technology; this attribute may have contributed to their exclusion from the genotyping panels.

JANARDAN P. PANDEY, PhD, Department of Microbiology and Immunology, Medical University of South Carolina, Charleston, South Carolina, USA. Address correspondence to Dr. J.P. Pandey, Department of Microbiology and Immunology, Medical University of South Carolina, Charleston, SC 29425, USA. E-mail: pandeyj@musc.edu

\section{REFERENCES}

1. Stone JH, Zen Y, Deshpande V. IgG4-related disease. New Engl J Med 2012;366:539-51.

2. Jefferis R, Lefranc MP. Human immunoglobulin allotypes: Possible implications for immunogenicity. MAbs 2009;1:332-8.

3. Steinberg AG, Morell A, Skvaril F, van Loghem E. The effect of $\mathrm{Gm}$ (23) on the concentration of IgG2 and IgG4 in normal human serum. J Immunol 1973;110:1642-5.

4. Oxelius VA, Hultquist C, Husby S. Gm allotypes as indicators of non-atopic and atopic bronchial asthma. Int Arch Allergy Immunol 1993;101:66-71.

5. Pandey JP. Immunoglobulin GM and KM allotypes and vaccine immunity. Vaccine 2001;19:613-7.

6. Pandey JP, Morais CG, Fontes CJ, Braga EM. Immunoglobulin GM $3235,13,14$ phenotype is strongly associated with IgG1 antibody responses to Plasmodium vivax vaccine candidate antigens PvMSP1-19 and PvAMA1. Malar J 2010;9:229.

7. van der Neut Kolfschoten M, Schuurman J, Losen M, Bleeker WK, Martínez-Martínez P, Vermeulen E, et al. Anti-inflammatory activity of human IgG4 antibodies by dynamic Fab arm exchange. Science 2007;317:1554-7.

8. Brusco A, Saviozzi S, Cinque F, DeMarchi M, Boccazzi C, de Lange G, et al. Molecular characterization of immunoglobulin G4 gene isoallotypes. Eur J Immunogenet 1998;25:349-55.

9. Labrijn AF, Rispens T, Meesters J, Rose RJ, den Bleker TH, Loverix S, et al. Species-specific determinants in the $\mathrm{IgG} \mathrm{CH} 3$ domain enable Fab-arm exchange by affecting the noncovalent CH3-CH3 interaction strength. J Immunol 2011;187:3238-46.

10. Pandey JP. Genomewide association studies and assessment of the risk of disease. N Engl J Med 2010;363:2076-7.

11. Pandey JP. Candidate gene approach's missing link. Science 2010;329:1148

J Rheumatol 2012;39:10; doi:10.3899/jrheum.120671 